\title{
Evaluación de las vulnerabilidades y potencialidades del paisaje en el municipio de Sacapulas, Quiché, Guatemala
}

\author{
The assessment of vulnerabilities and landscape potentials \\ in the municipality of Sacapulas, Quiche, Guatemala \\ David Barrios ${ }^{1 *}$, Andy Rodríguez ${ }^{1}$, Manolo García ${ }^{2}$ \\ ${ }^{1}$ Facultad de Arquitectura y ${ }^{2}$ Facultad de Ciencias Químicas y Farmacia, \\ Universidad de San Carlos de Guatemala, Guatemala.
}

*Autor al que se dirige la correspondencia: david.barrios@farusac.edu.gt

Recibido: 18 de abril 2017 / Revisión: 07 de octubre 2017 / Aceptado: 14 de diciembre 2017

\section{Resumen}

$\mathrm{E}$ 1 departamento de El Quiché forma parte de un corredor seco, el cual limita sus capacidades agrícolas y de desarrollo, al mismo tiempo que posee importantes remanentes de arquitectura residencial tradicional rural de adobe y teja asociados al paisaje del altiplano con elementos representativos del bosque seco y especies endémicas. Estos remanentes han ido desapareciendo y ya son escasos en el país. El presente estudio determinó la vulnerabilidad paisajística desde un enfoque multidisciplinario, por medio de una investigación práctica explicativa. El resultado obtenido fue conocer la vulnerabilidad paisajística del municipio de Sacapulas recabada en cartografía georreferenciada, como una herramienta relevante para la toma de decisiones para proteger y/o potenciar el uso del paisaje con un enfoque de valoración patrimonial y de desarrollo sostenible. Se utilizó para análisis de paisaje la determinación de unidades de características homogéneas y áreas de visibilidad asociada al relieve desde un eje ubicado en la carretera principal, el método de análisis se organizó en tres niveles: (1) elementos primarios de la percepción, (2) de la percepción elaborados para el diagnóstico y (3) de la percepción para la toma de decisión. Dicho proceso utiliza como base cartografía digital georreferenciada. Se obtuvo un mapeo de vulnerabilidad visual y paisajística. El principal resultado es la cartografía que indica las áreas con mayor vulnerabilidad paisajística la cual permite a instituciones y tomadores de decisiones tomar en cuenta el valor paisajístico que esta puede tener en cuanto a ser intervenida en cualquier momento.

Palabras claves: Calidad de paisaje, unidades de paisaje, vulnerabilidad y potencialidad del paisaje, percepción visual

\section{Abstract}

$\mathrm{T}$

The department of El Quiché is part of a dry corridor, which limits its agricultural and development capabilities, at the same time it has important remnants of traditional rural residential architecture of adobe and tile associated with the highland landscape with representative elements of the dry forest and endemic species. These remnants have been disappearing and are already scarce in the country. The present study determined the landscape vulnerability from a multidisciplinary approach, through an explanatory practical investigation. The result obtained was to know the landscape vulnerability of the municipality of Sacapulas collected in geo-referenced cartography, as a relevant tool for making decisions to protect and / or enhance the use of the landscape with a focus on patrimonial valuation and sustainable development. The determination of units with homogeneous characteristics and visibility areas associated with the survey from the main location was used for landscape analysis, the analysis method was organized into three levels: (1) primary elements of perception, (2) perception elaborated for the diagnosis and (3) of the perception for the decision making. This process uses georeferenced digital cartography as a base. A mapping of visual and landscape vulnerability was obtained. The main result is the cartography that indicates the areas with greater landscape vulnerability that allows institutions and decision makers to take into account the landscape value that it can have as soon as it is intervened at any time.

Keywords: Landscape quality, landscape's vulnerability and potentiality, landscape units, visual perception 


\section{Introducción}

El municipio de Sacapulas ubicado en la parte suroccidental del departamento de El Quiché, posee un importante remanente de vivienda tradicional en adobe $\mathrm{y}$ teja integrado a un paisaje montañoso seco. El paisaje integral ha sido valorado como un elemento importante de desarrollo desde hace ya varias décadas (Souto, 2011) en otras latitudes como, España (Marín-Yaseli \& Nogués-Bravo, 2001; Silva Pérez, 2014), México (Bollo Manent, Hernández Santana, \& Méndez Linares, 2010), Argentina (Ferraro \& Zulaica, 2011), Cuba (La O, Salinas, \& Licea, 2012) entre otras. Se ha tratado de promover y proteger de su degradación tanto física como cultural la cual muchas veces pone en peligro la calidad visual del mismo. Como apuntan Aguilera, Batista, Bastola y Rojas:

"La degradación reduce la calidad de paisaje entendiendo esta como la principal característica para su conservación y definida sobre las bases de sus valores ecológico perceptivo y cul- tural. Esta reducción de la calidad del paisaje es proporcional a la intensidad del impacto y está relacionada con el grado de modificación entre otros factores debido al contraste en tamaño forma o color" (2016).

Guatemala no es la excepción viéndose destruidos numerosos paisajes urbanos y rurales que poseían elevado valor patrimonial, histórico y natural. La armonía visual, es decir la tendencia a la integración, interrelación y concordancia de un elemento con otro (Briceño, Contreras, \& Owen, 2012) del paisaje natural de Sacapulas, está siendo intervenido por la urbanización no planificada y protagonizada por sistemas constructivos de block y concreto, instalaciones de vallas publicitarias, eléctricas y de telecomunicaciones, entre tantas más, que están poniendo en riesgo su calidad paisajística. Como se puede entender al leer a Sánchez (2007) la falta de planificación rural y urbana, la urbanización no planificada y la consecuente pérdida de la calidad paisajística, son resultado de la no existencia de políticas que las contrarresten, falta de control y presencia

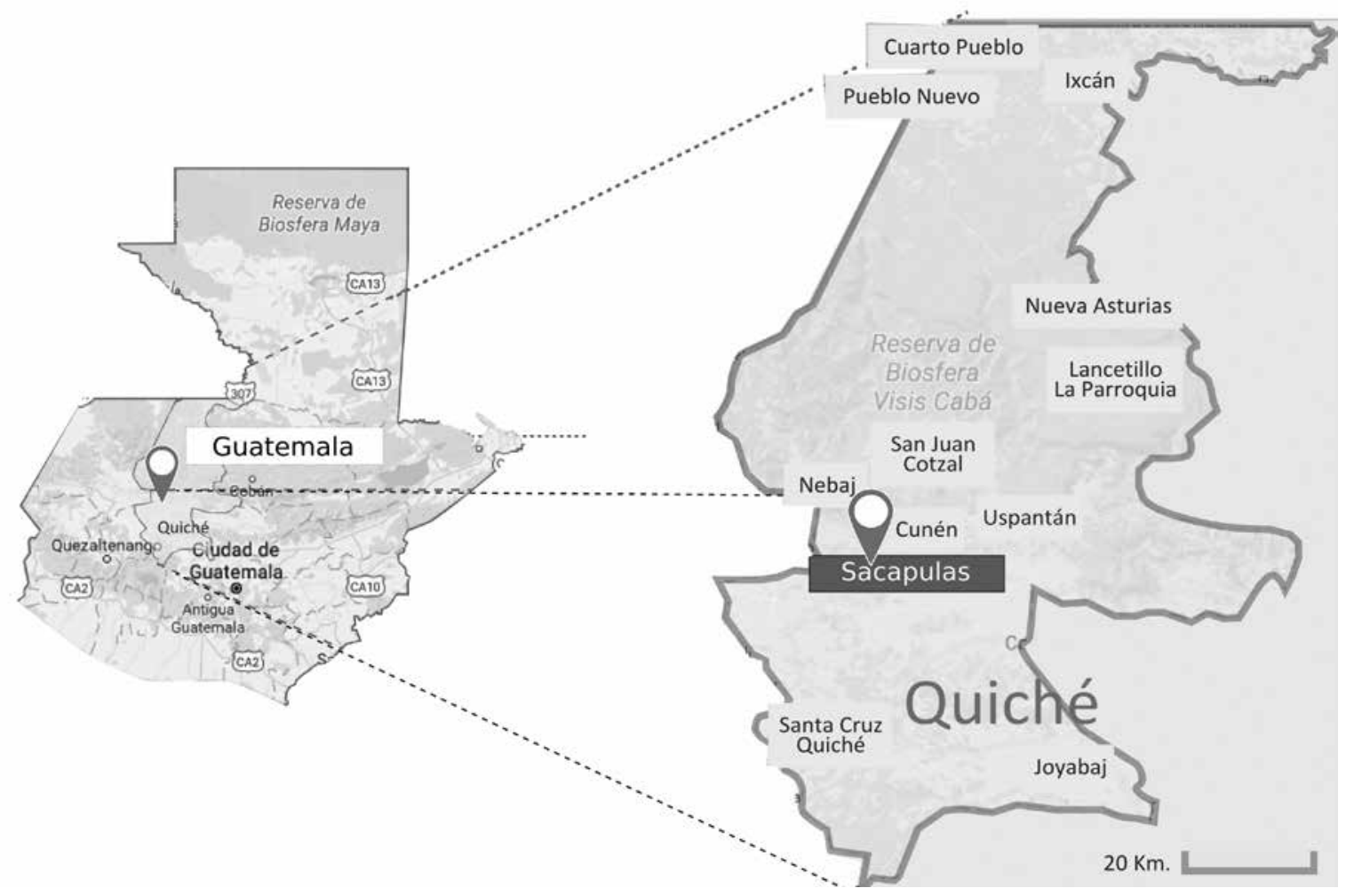

Figura 1. Ubicación del municipio de Sacapulas, Quiché, Guatemala. 
por parte del estado, falta de reglamentación que haga cumplir aquellas pocas políticas relacionadas.

Por medio de esta investigación, la Universidad de San Carlos de Guatemala (Usac) aporta información georreferenciada y jerarquizada de elementos con potencialidad y con deterioro paisajístico, usando como eje de análisis la carretera principal que atraviesa el municipio. Para Sacapulas y otras regiones interesadas, a futuro, es útil como insumo técnico para la toma de decisiones para proteger $\mathrm{y} / \mathrm{o}$ potenciar el uso del paisaje con un enfoque de valoración patrimonial y de desarrolo sostenible. El paisaje es determinante para la calidad de vida social. Por ello, la innovación metodológica de este estudio y el uso de sus resultados puede posicionar a Sacapulas como un municipio vanguardista en la planificación de su entorno escénico, en pro de la calidad de vida de sus pobladores y sin dañar su patrimonio natural o cultural, principal eje económico del lugar.

\section{Materiales y métodos}

\section{Delimitación geográfica}

El área de estudio abarca todo el municipio de Sacapulas (Figura 1), sin embargo, según el método las unidades se analizaron por visibilidad desde la carretera principal que atraviesa la zona urbana de Sacapulas y que comunica a Santa Cruz del Quiché y Nebaj.

La metodología utilizada fue una adaptación de tres niveles propuestos por Gómez (2012).

\section{Nivel 1. Elementos primarios de la percepción}

Como primer paso se llevó a cabo la delimitación de las unidades del paisaje utilizando como base el método semi-automatizado sugerido por Priego, Bocco, Mendoza y Garrido (2008),

Posteriormente se estimó el área aproximada de cada una en $\mathrm{km}^{2}$ (Tabla 1). Complementariamente, se llevó a cabo el conteo de viviendas y templos a partir de sus características culturales basadas en materiales, orden, ritmo, técnica, forma, orientación, modularidad habitacional, agrupación funcional, arqueología; relación con su época de construcción y uso, principalmente religioso, entre otras. Esto se hizo por medio de fotografías satelitales planas en blanco y negro, trabajadas por georreferenciación en el programa abierto Google earth (s.f.) con velocidad de animación de vuelo me- dia, configurado a kilómetros y metros, con un zoom de capacidad en pantalla de $1.2 \mathrm{~km}$. a $4.5 \mathrm{~km}$, para el análisis y una aproximación de pantalla que abarcó hasta $10 \mathrm{~km}$ para los polígonos de síntesis de conteos, geo referenciando cada elemento antrópico, utilizando archivos KML, se tomaron 20 gráficas de síntesis de conteo cuya síntesis se encuentra en la Tabla 2.

Además, existen elementos como bodegas y baños de vapor que no se contabilizaron. Las áreas urbanas solo fueron tomadas en cuenta como manchas con valor visual para el método de este estudio, y separando el ordenamiento territorial del urbano. Se recorrieron los puntos clave de la carretera para documentar con video y fotografía los lugares. Los hallazgos y metodología se validaron con especialistas. El método se adaptó a las herramientas digitales disponibles como Arcgis (Environmental Systems Research Institute [Esri], 2012), a los indicadores y parámetros existentes en el país, y con las distintas disciplinas del equipo, en campo se adaptó por medio personal bilingüe y local, los resultados se discutieron de forma multidisciplinaria en una presentación de resultados ante representantes de distintos centros de investigación.

\section{Nivel 2. Elementos primarios de la percepción elaborados para el diagnóstico}

Se analizó la visibilidad usando el programa Arc Map versión 10, las herramientas Cost Distance (costo por distancia) y Viewshed (cuenca visual) de la extensión Spatial Analyst (Esri, 2012) se calculó la distancia desde la carretera hacia todo el municipio y la visibilidad desde la carretera, respectivamente. Cada uno de estos mapas fue reclasificado en categorías en una escala de uno a cinco y posteriormente fueron sumados en un mapa de visibilidad. Por medio de matrices y pobladores, también se valoraron los elementos antrópicos significativos ubicados según los 16 puntos del eje de análisis, con potencial emisor de vistas: puntos valiosos del relieve desde donde la penetración visual es mayor. Esta valoración se enfocó en el razonamiento de la vida local y su historia, relación con su entorno, edad y género. La calidad de las unidades estuvo acotada por las distancias corta, mediana y lejana en los distintos planos visuales cercanos, medios o lejanos; por morfología y visibilidad del relieve. El análisis psicosemiótico se realizó a partir de varios aspectos técnicos de color, alfabetidad visual, de composición y otros elementos escénicos, para construir los perfiles de valoración "me gusta" y "no me gusta" de las fotografías de los paisa- 
Tabla 1

Unidades de paisaje visibles desde la carretera para el municipio de Sacapulas y su extensión aproximada

\begin{tabular}{|c|c|c|c|c|c|}
\hline Unidad & $\begin{array}{c}\text { Sub } \\
\text { unidad }\end{array}$ & $\begin{array}{l}\text { Disección } \\
\text { vertical }\end{array}$ & Descriptor & $\%$ & Extensión $\left(\mathrm{km}^{2}\right)$ \\
\hline I & & $\begin{array}{c}\text { Montañas medianamente } \\
\text { diseccionadas }\end{array}$ & Chuacús 1 & 27.32 & 89.17 \\
\hline II & & $\begin{array}{c}\text { Montañas medianamente } \\
\text { diseccionadas }\end{array}$ & Cuchumatanes & 25.26 & 82.46 \\
\hline \multirow[t]{3}{*}{ III } & A & $\begin{array}{c}\text { Montañas medianamente } \\
\text { diseccionadas }\end{array}$ & Chuacús 2 & 40.13 & 131.01 \\
\hline & B & $\begin{array}{c}\text { Montañas medianamente } \\
\text { diseccionadas }\end{array}$ & Chutixtiox & 0.10 & 0.33 \\
\hline & $\mathrm{C}$ & $\begin{array}{l}\text { Montañas fuertemente } \\
\text { diseccionadas }\end{array}$ & Alta pendiente & 0.35 & 1.14 \\
\hline \multirow[t]{3}{*}{ IV } & A & $\begin{array}{l}\text { Montañas ligeramente } \\
\text { diseccionadas }\end{array}$ & Río Negro 1 & 2.82 & 9.21 \\
\hline & $\mathrm{B}$ & $\begin{array}{l}\text { Planicies acolinadas fuer- } \\
\text { temente diseccionadas }\end{array}$ & Río Negro & 0.21 & 0.68 \\
\hline & $\mathrm{C}$ & $\begin{array}{l}\text { Montañas ligeramente } \\
\text { diseccionadas }\end{array}$ & Río Negro 3 & 2.36 & 7.71 \\
\hline $\mathrm{V}$ & & $\begin{array}{c}\text { Montañas ligeramente } \\
\text { diseccionadas }\end{array}$ & Río Negro 2 & 1.34 & 4.36 \\
\hline \multirow[t]{2}{*}{ VI } & & $\begin{array}{c}\text { Montañas ligeramente } \\
\text { diseccionadas }\end{array}$ & Rancho de teja & 0.12 & 0.38 \\
\hline & & total & & 100.00 & 326.45 \\
\hline
\end{tabular}

Tabla 2

Totales de cantidad de vivienda por material de construcción

\begin{tabular}{ccccccccc}
\hline Unidad & Teja & $\%$ & Lámina & $\%$ & Losa & $\%$ & Total & $\%$ \\
\hline 1 & 208 & 19 & 414 & 14 & 46 & 14 & 668 & 15 \\
2 & 256 & 23 & 901 & 31 & 87 & 27 & 1,244 & 29 \\
3 & 145 & 13 & 353 & 12 & 10 & 3 & 508 & 12 \\
4 & 331 & 30 & 1,027 & 35 & 176 & 54 & 1,534 & 35 \\
5 & 158 & 14 & 195 & 7 & 8 & 2 & 361 & 8 \\
6 & 17 & 2 & 14 & 0 & 0 & 0 & 31 & 1 \\
& 1115 & 100 & 2,904 & 100 & 327 & 100 & 4,346 & 100 \\
\hline
\end{tabular}

Nota. En todos los polígonos visibles en patrón disperso. 
jes muestra. Estas fotografías contienen hasta 80 descriptores y consisten en vistas de paisajes con distintas características como por ejemplo con vegetación o sin ella permitiendo a la persona escoger fácilmente.

Posteriormente se preguntó: ¿Por qué le gustaron más las fotografías que eligió así...? y ¿por qué le gustaron menos las fotografías que eligió así...? ...de un grupo de 10 imágenes seleccionadas aleatoriamente para cada informante, de un banco de más de 50 fotografías. Esto permitió identificar los paisajes con potencial y sin potencial, respectivamente. Dos estudios piloto de 40 personas cada una, validaron la eficacia del proceso anterior y proporcionaron una varianza de 0.18 para el cálculo muestral a partir de población de 42 mil personas, $5 \%$ de confiabilidad, $10 \%$ de error. Dada la alta heterogeneidad que representa esa varianza se optó por estimar directamente con el máximo de 0.5:0.5 equivalente a 0.25 .

La muestra calculada fue de 96. La segregación fue por edades en clases de edad de 10 años en adelante, por bloques de escolaridad, por el último nivel cursado: primaria, secundaria, diversificado, universidad o superior e igual proporción entre mujeres y hombres. Se incluyeron personas de lugares aledaños a Sacapulas. Pero, por la homogeneidad de sus respuestas con los lugareños, se sumaron para formar una muestra común. Lo anterior se comparó con los análisis de las vistas georreferenciadas; con los elementos primarios de la percepción elaborados para el diagnóstico y elementos antrópicos significativos, nivel 2, para construir los perfiles.

\section{Nivel 3. Elementos primarios de la percepción para la toma de decisión}

Se estimó el índice de calidad visual intrínseca del paisaje, con base en la metodología empleada por Paz, Escribano, López y Sánchez (2005) compuesta por los factores (a) vegetación y uso del suelo, (b) agua superficial, (c) incidencia antrópica y (d) singularidad. Por último, se asignaron valores proporcionales de acuerdo a la visibilidad (áreas muy visibles $=100 \%$, visibles $=50 \%$ y poco visibles $=25 \%$ ). El análisis y geoposicionamiento de elementos antrópicos significativos se realizó a partir de los polígonos clasificados por nivel de visibilidad en el nivel 2, a partir de fotografías satelitales (Tabla 2), para cruzar la información de visibilidad con el nivel de pertenencia a la tradición arquitectónica.

Se estimaron los índices de fragilidad por (a) movimiento, (b) exposición visual, y (c) cobertura del suelo, los cuales componen al integrarse el índice de fragilidad por factores biofísicos. Este índice fue combinado con el índice de fragilidad por factores de visibilidad compuesto por (a) intervisibilidad y (b) accesibilidad, utilizando como base la metodología de valoración empleada por Paz y colaboradores (2005). Al mapa resultante se le asignaron valores proporcionales de acuerdo a la visibilidad (áreas muy visibles $=$ $100 \%$, visibles $=50 \%$ y poco visibles $=25 \%$ ).

\section{Resultados}

Luego del método aplicado se obtuvieron resultados que ahora se organizan también en los tres niveles que lo componen y pueden visualizarse en la cartografía que se elaboró.

Nivel 1. Elementos primarios de la percepción.

Se delimitaron seis unidades de paisaje para los paisajes del área de estudio en el municipio de Sacapulas (Figura 2).

La superficie del paisaje sacapulteco está dominado por zonas montañosas (Unidades 1,2 y 3 ) con áreas de menor pendiente en partes altas (Unidades 5 y 6) y otras asociadas al río Negro a una menor altitud (Unidad 4). Las viviendas son los elementos antrópicos más abundantes y pueden contarse según las características antes mencionadas como: tradición arquitectónica de teja y adobe, 1,209 unidades compuestas de varios módulos y anexos; elementos antrópicos pro tradición, 306 unidades que integran cada una varios módulos. Hay 669 unidades de concreto reforzado. Todas estas unidades se identificaron solo en las cuencas visuales del eje de análisis. Se ubicaron templos cristianos y sitios arqueológicos (Tablas 2 y 3 ).

\section{Nivel 2. Elementos primarios de la percepción} elaborados para el diagnóstico.

En el análisis espacial de visibilidad se estimaron las áreas de mayor visibilidad desde la carretera principal para el municipio de Sacapulas (Figura 3) la cual se constituyó en el eje de análisis de las unidades. El área de alta visibilidad con mayor extensión se ubica en zonas montañosas correspondientes a la Unidad 2. Estas zonas montañosas son visibles desde varias partes del recorrido hacia el poblado de Sacapulas. Además de 
Tabla 3

Conteo de elementos antrópicos significativos en unidades de paisaje

\begin{tabular}{cccc}
\hline Unidad & Nivel Visibilidad & Templos & Sitios Arqueológicos \\
\hline 1 & Visible & 9 & 3 \\
& Poco visible & 5 & 7 \\
2 & Muy visible & Visible & 5 \\
& Poco visible & 2 & 1 \\
& Muy visible & 1 & 4 \\
& Visible & 2 & 1 \\
& Poco visible & Visible & 6 \\
\end{tabular}

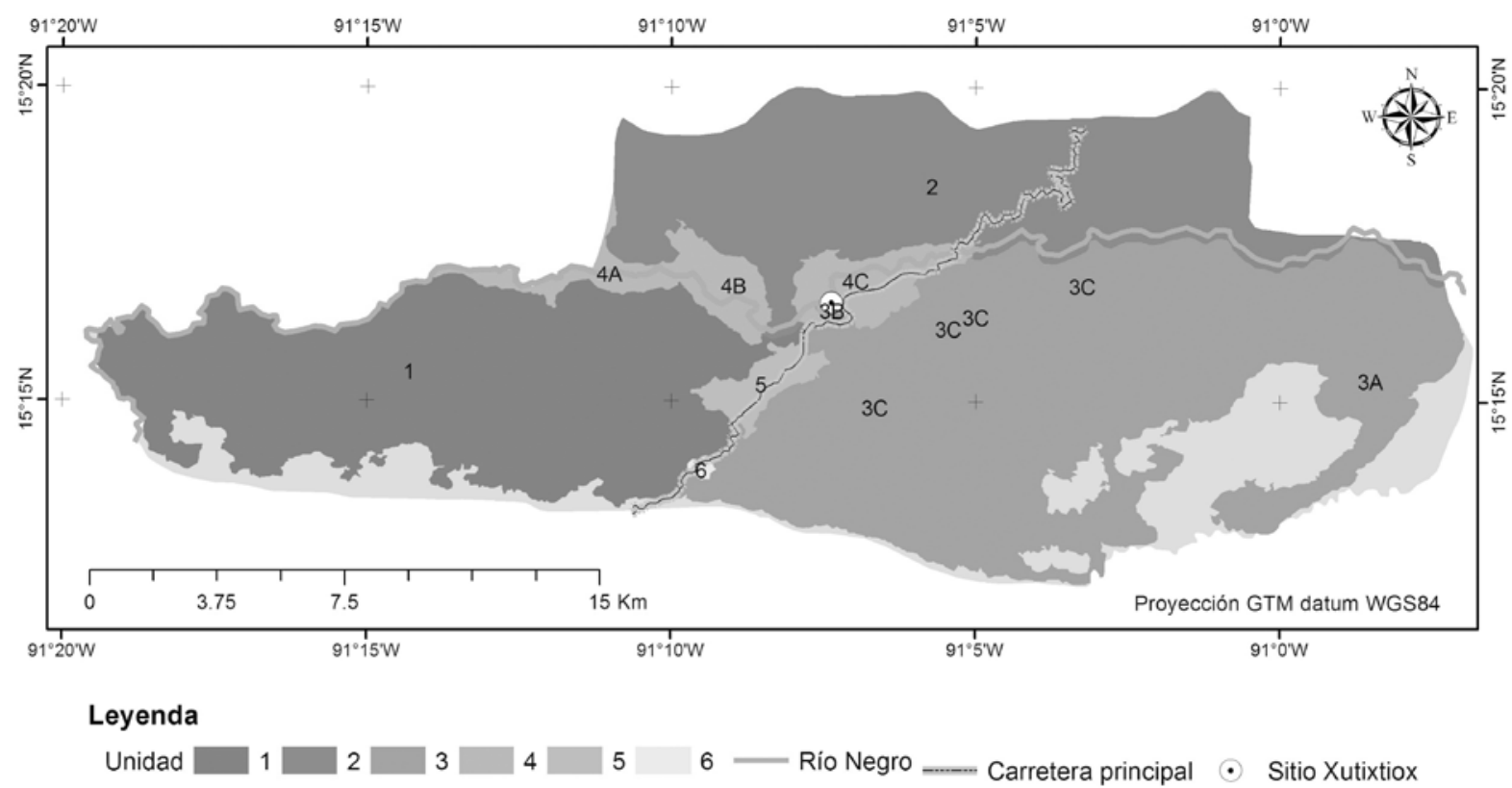

Figura 2. Unidades de paisaje para el municipio de Sacapulas. Cada unidad representa un color y las subunidades se representan con letras (A-C). 


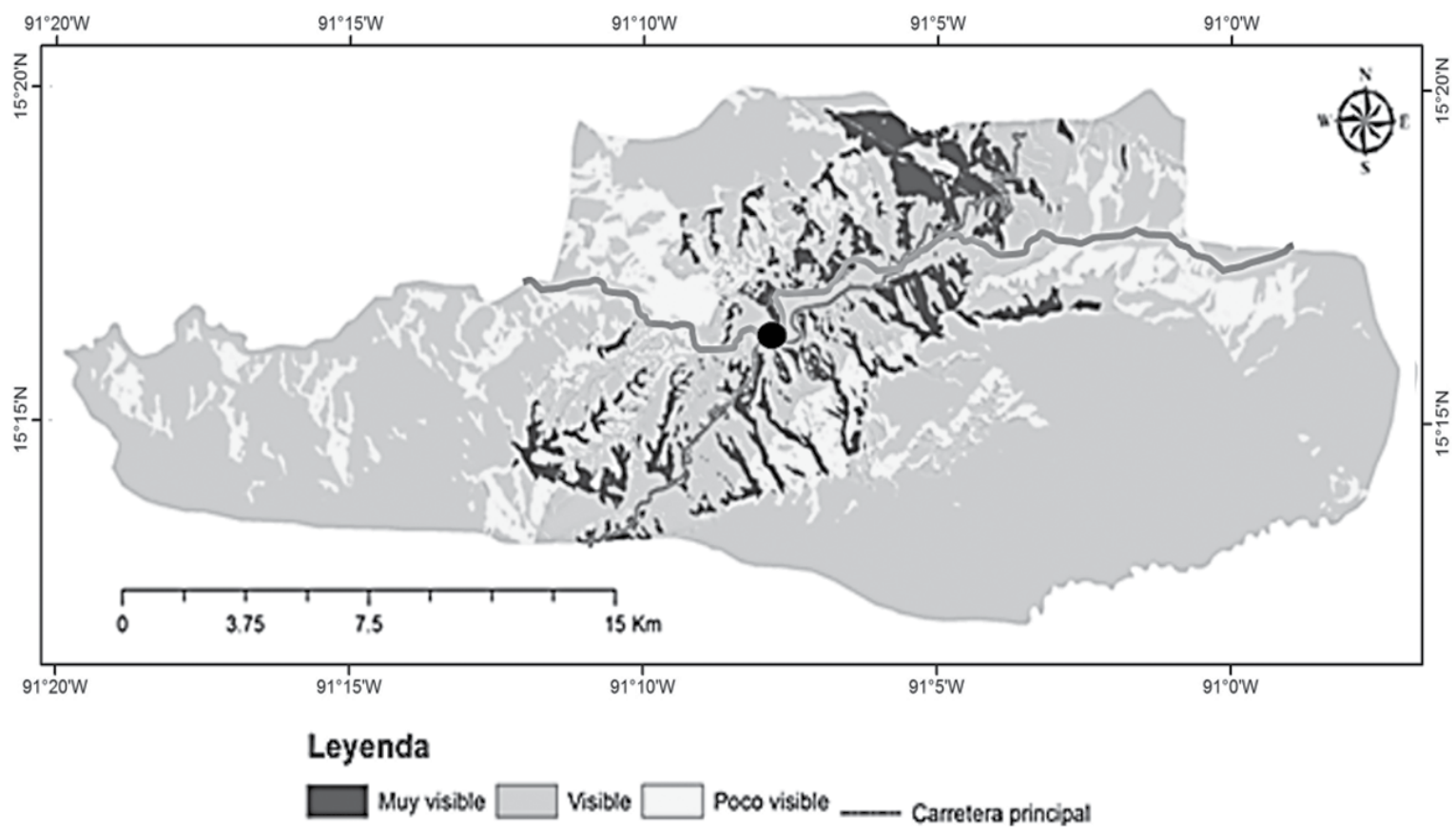

Figura 3. Visibilidad desde la carretera principal para el municipio de Sacapulas.

los elementos residenciales se georreferenciaron los visibles de tipo religioso y arqueológico. En las unidades ambientales uno y dos existen una mayor cantidad de templos y alcanzaron mayor nivel de valor por singularidad por estar en polígonos clasificados como visibles o muy visibles (Tabla 3 ). La valoración de singularidad por existencia de sitios arqueológicos en las unidades fue baja, ya que la mayoría no son visibles desde el eje de referencia y solo se sabe que están ubicados en todas las unidades de análisis, excepto el sitio arqueológico representativo por excelencia y cuyo asentamiento natural es pronunciadamente visible en la unidad 3, la ciudad fortaleza postclásica de Chutixtiox, rodeada por el río y por pronunciadas pendientes en tres de sus lados, forma un cerro de marcada notoriedad. En el lugar se realizan ceremonias de la religión ancestral.

\section{Nivel 2. Análisis psicosemiótico.}

El contraste entre las respuestas "Me gusta" y "No me gusta" obtuvo una proporción 0.3 - siendo las proporciones resultantes 0.6 y 0.3 , respectivamente, para $50(96 \%)$ de las 52 imágenes muestra (Figura 4).

Solo a partir de las primeras se pudo elaborar el perfil (de potencialidad), dada la homogeneidad de sus características (Tabla 4), con intervalos de confianza IC 95\% [0.52, 0.58]. Las proporciones más importantes fueron: Preferencia por el color cian grisáceo, medio obscuro; por el paisaje natural, con una frecuencia absoluta de 95 (96\%), $p=.96$ IC 95\% [0.88,>1], punto focal de las imágenes con una frecuencia absoluta de $86(90 \%), p=.9$ IC 95\% [0.82, 0.98] de elección y a nivel general con una frecuencia absoluta de 77 (80\%), $p=0.8$ IC $95 \%$ [0.72;0.88]; frecuencia absoluta de 53 $(55 \%), p=0.55$ IC 95\% $[0.47,0.63]$ de predilección por las líneas de fuerza inclinadas, respecto a la frecuencia absoluta de 38 (40\%), $p=0.4$ IC 95\% [0.32;0,48] de la horizontalidad de lectura visual esperada en un paisaje. La preferencia por los altos contrastes de luz con una frecuencia absoluta de $53(55 \%), p=0.55$ IC $95 \%$ [0.47;0.63]. La mayoría de elementos descriptibles como paisaje en la mitad inferior del plano de visión. Las visuales preferidas por la muestra son aquellas con relieve menos inclinado, con una mayor amplitud visual y que integran varios planos visuales, estando el observador situado en un área plana. El observador prefiere que lo que ve tenga riqueza de relieve y con riqueza de elementos naturales incluyendo pendientes fuertes de medianos y altos contrastes de luz. Lo que más prefirieron está entre cuatro y cinco planos de profundidad con tendencia a cuatro. Las tensiones dominantes por líneas 


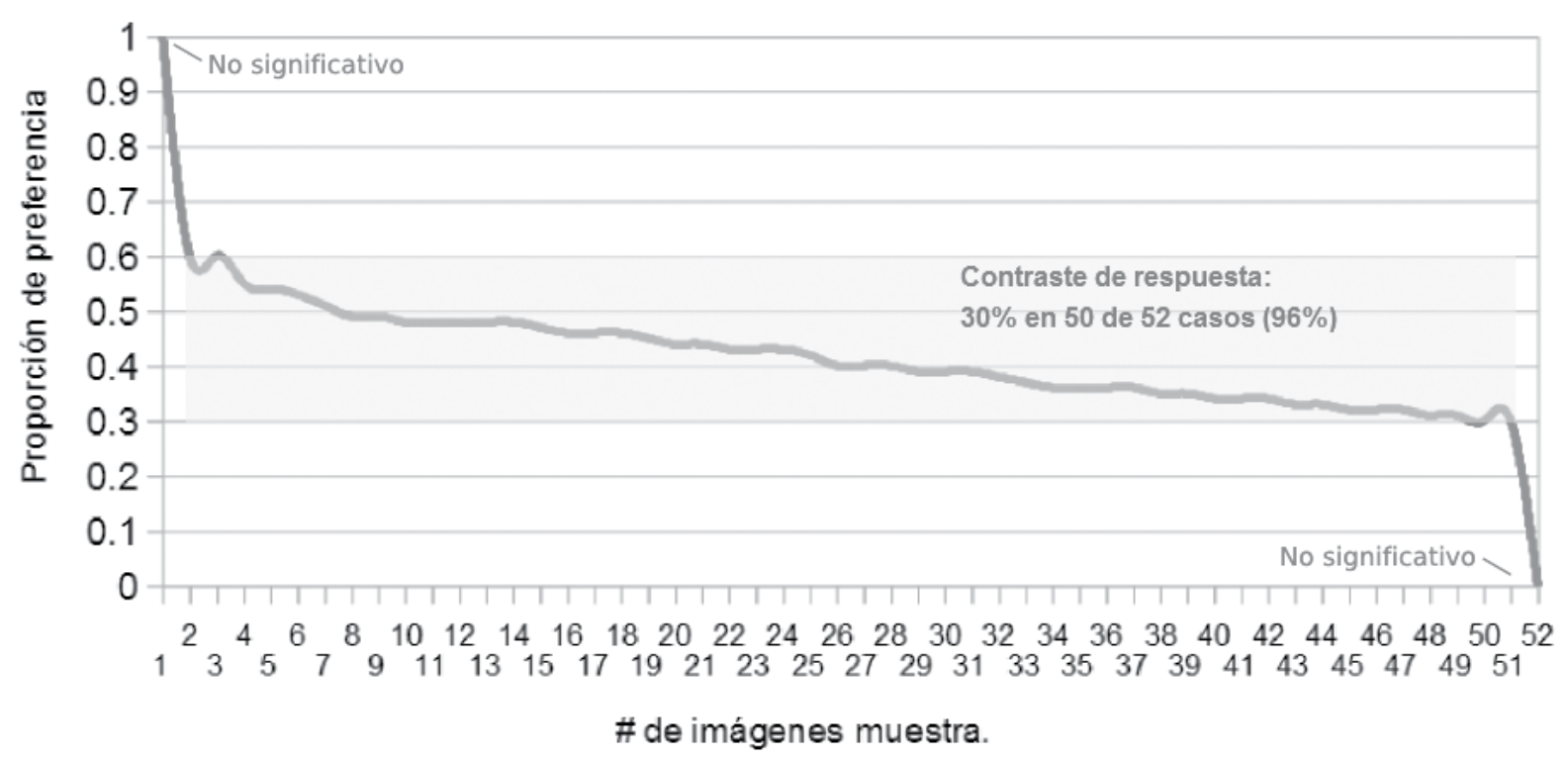

Figura 4. Proporción de preferencia de imágenes muestra.

Tabla 4

Análisis de cromático, a partir de histograma Cielab, para imágenes valoradas como paisaje

\begin{tabular}{cccc}
\hline Color & Media (Desv. estándar) & Varianza & Coeficiente de variabilidad \\
\hline L & $61(14)$ & 196 & 0.23 \\
a & $-3(9)$ & 81 & 3 \\
b & $-8(5.66)$ & 32 & 0.71 \\
\hline
\end{tabular}

Nota. Color L, de 0 a 100: obscuridad a claridad perceptuales, respectivamente. Color a, de -128 a +128 : verde a rojo perceptuales, respectivamente. Color $\mathrm{b}$, de $-128 \mathrm{a}+128$ : azul a amarillo perceptuales, respectivamente. Equivalencias en sistema HSB, donde $\mathrm{H}=$ Hue (Matiz), $\mathrm{S}=$ Saturation (Saturación), B=Brightness (Brillo): H=207 (Cián), $\mathrm{S}=17 \%$ (Grisáceo), B=64\% (Obscuro-medio)

de perspectiva y formas irregulares, fueron de $49(51 \%)$, $p=0.51$ IC $95 \%[0.43 ; 0.59]$ y $43(45 \%), p=.45$ IC $95 \%$ $=[0.37 ; 0.53]$ respectivamente La heterogeneidad de la evidencia cuantitativa de las variables psicosemióticas, invalidaron la construcción del perfil de vulnerabilidad. Sin embargo, se identificó 50 (52\%), $p=.52$ IC 95\% [0.44; 0.6$]$ de rechazo por la deforestación, erosión y sinónimos. Además, una proporción de 37 (38\%), $p=$ 0.38 IC 95\% [0.3;0.46] de menosprecio por la presencia de contaminación. Para los informantes, se refiere a basura, principalmente. Las respuestas de los profesiona- les fueron escasas, por el bajo número de especialistas en el tema y también muy variables, desestimando su valor como resultado.

\section{Nivel 3. Elementos primarios de la percepción} para la toma de decisión.

Estimación de la calidad visual intrínseca. De acuerdo a la metodología propuesta se estimó el índice para las unidades de paisaje visibles desde la carretera 
principal (Figura 3). Las áreas de mayor calidad están dominadas por zonas montañosas con cobertura de bosque de pino-encino ubicadas en las Unidades 1,2 y 3 (Figura 2). La subunidad 3B correspondiente al cerro donde ubica el sitio arqueológico Chutixtiox también presenta una alta calidad visual intrínseca. Es decir que posee alta valoración en los factores vegetación y uso del suelo, agua superficial, incidencia antrópica entre otros. Análisis de elementos antrópicos significativos (Nivel 3). Las unidades que más elementos antrópicos relacionados a la tradición arquitectónica presentan en polígonos con alta visibilidad son: $4,2,5$ y 3 respectivamente. Como polígonos con visibilidad están las unidades: 4, 2, 3 y 1 . Se puede ver como en cuanto a contener elementos antrópicos las unidades más importantes son las unidades 4, 2 y 1 pues aparecen las primeras dos en los primeros lugares y la 1 que aparece en los tres siempre a diferencia de otras que solo aparecen en uno o dos clasificaciones.

Con base en la estimación realizada las áreas con mayor fragilidad visual corresponden a zonas montañosas en las Unidades 1, 2 y 3 , zonas de menor pendiente en partes altas en las Unidades 5 y 6 , así como zonas asociadas al río Negro que son visibles desde la carretera en la Unidad 4 (Figura 5).

\section{Discusión}

\section{Nivel 1. Elementos primarios de la percepción.}

Una parte importante de los resultados se presentan como cartografía, por su fácil acceso a los técnicos de las instituciones y comunidades, relacionados al tema y, de quienes se espera el uso de los mismos, distinto de otras herramientas en formatos escritos o en tablas como los planes de desarrollo municipales (Secretaría General de Planificación Nacional \& Consejo Municipal de Desarrollo de Cuicuilco, 2010). Sacapulas tiene una importante cantidad de elementos habitacionales antrópicos de la tradición local y regional vernácula. Desde el punto de vista de la disciplina de la arquitectura y el ordenamiento territorial es importante preservar su existencia no solo como valor de identidad de las comunidades locales sino como un elemento único por su combinación con el entorno paisajístico,

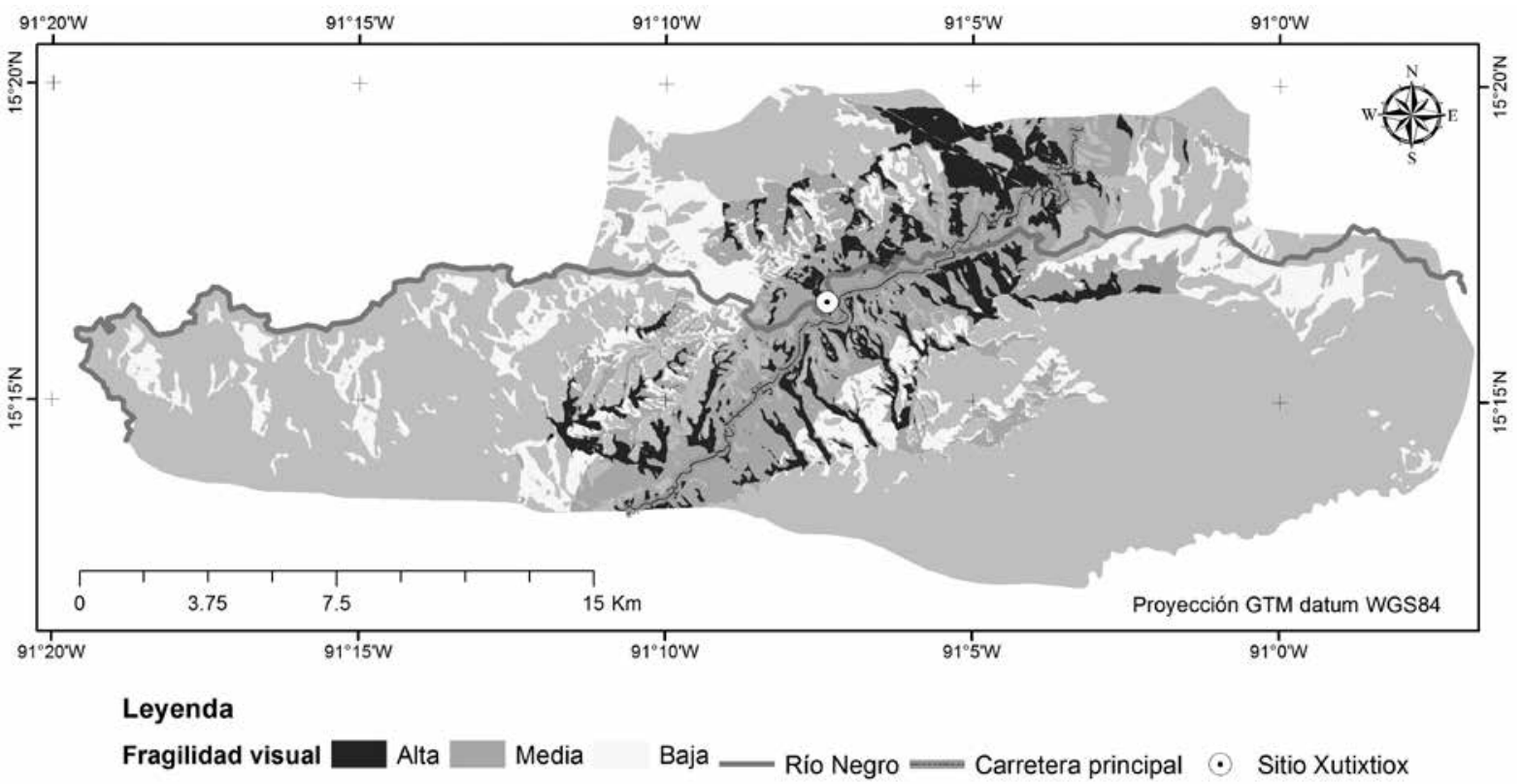

Figura 5. Índice de fragilidad visual 
combinación que, según algunos autores debe ser total e integral (Másmela, 2010).

La cantidad de elementos habitacionales recientes $\mathrm{y}$ actuales que se adapta de diversas maneras a las características de la tradición arquitectónica local es significativa ya que cuenta con 4,019 de 4,346 viviendas (Tabla 2) por lo que el paisaje a pesar del limitado nivel de desarrollo humano que implica rezago en diversos sectores como se menciona en su Informe Anual 2012 el Programa de las Naciones Unidas para el Desarrollo (PNUD, 2012), presenta un alto nivel de unidad tanto en técnica constructiva como en el aspecto formal, recurso paisajístico con el que otras regiones ya no cuentan.

El geoposicionamiento de los elementos antrópicos es un paso valioso en la consideración del paisaje, debido a sus elementos tangibles, cuantificables y localizables. Estos son importantes, no sólo por su utilidad habitacional para los pobladores, sino por representar la interpretación social del entorno, a través de soluciones técnicas, interpretaciones formales y distribuciones espaciales. Es decir, permiten el reconocimiento de las características del grupo social por medio de sus rasgos. $\mathrm{El}$ alto porcentaje de elementos antrópicos pertenecientes o relacionados a una tradición arquitectónica puede interpretarse como una oportunidad de gestión a causa de unidades que deben ser valoradas dentro de la larga lista de municipios del país, donde el haberlos perdido ha significado la desvalorización paisajística. La pérdida de grandes grupos representativos contenedores de valores culturales debe ser detectada por las distintas ciencias y disciplinas. Basta ver como entornos con calidades tradicionales de arquitectura han sido protegidas $\mathrm{y}$ han significado desarrollo humano y económico para sus comunidades (Cano, 2006).

\section{Nivel 2. Elementos primarios de la percepción elaborados para el diagnóstico.}

En cuanto a los resultados obtenidos en este nivel podemos decir que la valoración dada a los elementos antrópicos in situ por personas locales y técnicos del equipo enriqueció los resultados y su análisis. Sin embargo, no siempre la diferencia entre las opiniones, permitieron elaborar conclusiones polarizadas. Por ejemplo, el 0.3 de contraste entre las preferencias y las no preferencias de los paisajes no permitió elaborar conclusiones significativas para el posterior Nivel 3: toma de decisiones. De acuerdo con lo anterior, tampoco el perfil de características de potencialidad paisa-

Tabla 5

Proporción (p) de componentes alfabéticos visuales, para imágenes valoradas como paisaje

\begin{tabular}{cccccccccccc}
\hline Componente & $f$ & $\%$ & Componente & $f$ & $\%$ & Componente & $f$ & $\%$ & Componente & $f$ & $\%$ \\
\hline CV1 & 92 & 96 & LF5 & 0 & 0 & PD2 & 1 & 1 & 3DA3 & 2 & 2 \\
CV2 & 0 & 0 & LF6 & 0 & 0 & PD3 & 0 & 0 & VL1 & 19 & 20 \\
CV3 & 4 & 4 & PP1 & 0 & 0 & PD4 & 0 & 0 & VL2 & 24 & 25 \\
PF1 & 86 & 90 & PP2 & 1 & 1 & PD5 & 0 & 0 & VL3 & 53 & 55 \\
PF2 & 0 & 0 & PP3 & 19 & 20 & PD6 & 79 & 82 & MA1 & 0 & 0 \\
PF3 & 1 & 1 & PP4 & 24 & 25 & 3DN1 & 25 & 26 & MA2 & 0 & 0 \\
LF1 & 38 & 40 & PP5 & 29 & 30 & 3DN2 & 58 & 60 & MN1 & 0 & 0 \\
LF2 & 0 & 0 & PP6 & 14 & 15 & 3DN3 & 13 & 14 & MN2 & 0 & 0 \\
LF3 & 53 & 55 & PP7 & 0 & 0 & 3DA1 & 11 & 11 & TG1 & 0 & 0 \\
LF4 & 5 & 5 & PD1 & 8 & 8 & 3DA2 & 9 & 9 & TG2 & 0 & 0 \\
\hline
\end{tabular}

Nota. Nomenclatura: CV\#, contenido visual; PF\#, punto focal; LF\#, líneas de fuerza; PP\#, planos de profundidad; PD\#, planos de detalle visibles; 3DN\#, textura natural; 3DA\#, textura artificial; VL\#, volumen; MA\#, movimiento artificial;

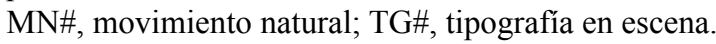


Tabla 6

Proporción (p) de aspectos compositivos visuales, para imágenes valoradas como paisaje

\begin{tabular}{cccccccccccc}
\hline Componente & $f$ & $\%$ & Componente & $f$ & $\%$ & Componente & $f$ & $\%$ & Componente & $f$ & $\%$ \\
\hline XY1 & 92 & 96 & SM1 & 0 & 0 & TN1 & 1 & 1 & TN5 & 2 & 2 \\
XY2 & 0 & 0 & SM2 & 0 & 0 & TN2 & 0 & 0 & TN6 & 19 & 20 \\
XY3 & 4 & 4 & RA1 & 0 & 0 & TN3 & 0 & 0 & & \\
XY4 & 86 & 90 & RA2 & 1 & 1 & TN4 & 0 & 0 & & \\
\hline
\end{tabular}

Nota. Nomenclatura: XY\#, peso cartesiano; SM\#, simetría; RA\#, regla de aire; RN\#, tensión

jístico (Tablas 5 y 6) tendría valor significativo para la interpretación, a pesar de la cantidad de variables independientes que contiene. Sin embargo, como una matriz innovadora, sí es importante metodológicamente y se recomienda aplicarla en estudios futuros para que motive a la exploración y el mejoramiento de los mismos.

Los resultados a partir de las respuestas abiertas de porqué gustaron o no las imágenes seleccionadas por los encuestados, indican la apreciación de la naturaleza en los paisajes, entre ellos el paisaje forestal y libre de contaminación, refiriéndose principalmente a basura expuesta (Figuras 6 y 7).

Este resultado tiene varias explicaciones: (a) $\mathrm{La}$ interiorización del paisaje verde en los juicios de valor positivos de la gente, dada las características de "lugareños" de la mayoría de la población informante. (b) La posible conexión de los elementos naturales con el inconsciente colectivo de la población a través del arquetipo de la madre, citado por Jung (1959), que hace referencia a la necesidad innata del ser humano de estar aferrado a algo, y que daría lugar a la re significación de los componentes del entorno natural inmediato como entes poderosos, dadores, preservadores y/o protectores de la vida. "...el pueblo sacapulteco tiene la creencia de que en la montaña habitan los espíritus, esto ha sido transmitido de nuestros abuelos", relató J. Vásquez (comunicación personal, 2016), promotor cultural. Esta descripción sustenta esa explicación dicotómica entre lo atractivo y lo terrible de la figura maternal que ama y reprende al mismo tiempo: atracción y temor en una sola figura. (c) El éxito de las campañas de comunicación que a través de los años se han sumado al bombardeo psicológico masivo de reforestar, no talar, cuidar el ambiente, sembrar árboles, entre otras.

El deterioro ambiental es una crisis mundial que casi ha convertido al árbol en el arquetipo moderno de la salvación del planeta, como catalizador del agua, oxígeno, biodiversidad y salud de los suelos, necesarios para la preservación de la vida. Las campañas de comunicación que han sensibilizado al respecto, también han mal informado acerca de otras formas de conservación de la vida, también naturales. Un ejemplo de estas campañas es la que lanzara la Organización No Gubernamental Alternativa en Peru en el 2010: 10000 compromisos por el agua. Analizando la preferencia de imágenes con bosques de color verde, resalta el valor por los bosques de pino-encino, en contraste con el de los bosques secos que presentan tonalidades opacas y una estructura vertical de menor altura. El desconocimiento de la riqueza natural de los bosques secos puede influir en que estos no sean apreciados positivamente de la misma manera que otros ecosistemas. En el estudio de Véliz y Méndez (2008) se documentaron 287 especies pertenecientes a 73 familias de plantas, para este ecosistema en el área de estudio, incluyendo a los arbustos Verbesina guatemalensis Donn. Sm. y Zexmenia phyllocephala (Hemsl.) Standl \& Steyerm, especies endémicas de las regiones semiáridas de Guatemala.

La calidad visual depende de la capacidad de cada elemento para diferenciarse dentro de otros. La proporción de 0.55 de preferencia por paisajes con altos contraste de luz reafirman esto como "potencial paisajístico", provocando los mejores avistamientos en horas más cercanas al crepúsculo y al ocaso; contrario a las horas cercanas al medio día (12:00 h.) cuando la volumetría de los elementos lucirá aplanada. A mayor contraste, mayor tensión perceptual y más probabilidad agrado y mejor apreciación de la tridimensionalidad del espacio. Dicha tensión se reforzará en lugares con líneas de perspectiva y formas irregulares evidentes (0.51 y 0.45$)$.

El dominio de pesos visuales en la mitad inferior del área de visión podría ser obvio por ser paisaje el objeto de estudio. Sin embargo, la omisión de la descripción del cielo en las respuestas en favor y en contra 


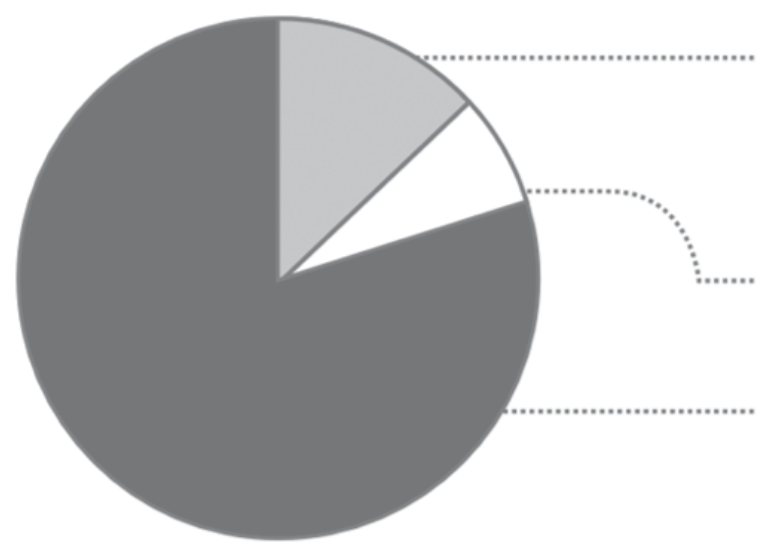

\author{
$13 \% \quad$ Aspectos varios: Clima \\ agradable; paisaje \\ bonito...
}
$7 \% \quad$ No hay contaminación, se ve limpio...

$80 \%$

\author{
Hay árboles, bosques, \\ llano, monte, naturaleza, \\ colores: lo verde, \\ montañas, ríos...
}

Figura 6. Porcentaje de cualificadores de potencialidades del paisaje.

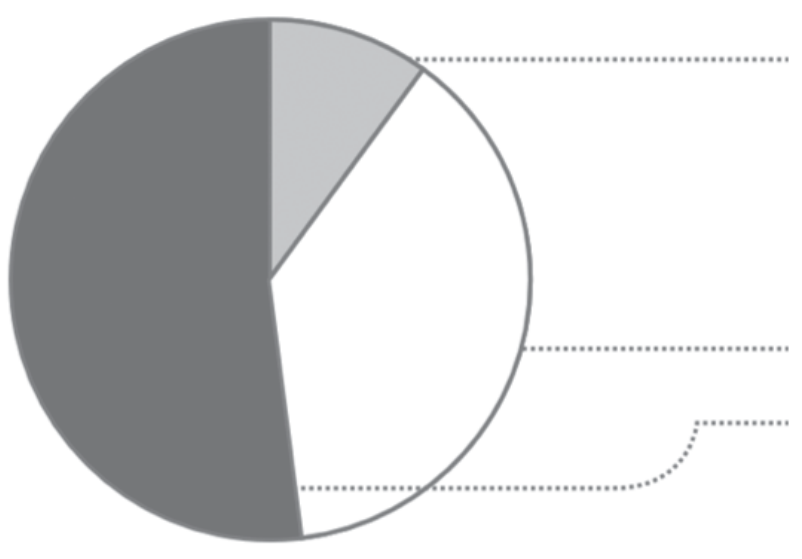

$10 \%$

Aspectos varios: presencia antrópica; construcciones, propaganda política; no hay casas, muchos barrancos...

Hay contaminación..

$52 \%$ Hay deforestación, pocos árboles, erosión, sequía, desierto...

Figura 7. Porcentaje de cualificadores de vulnerabilidades del paisaje.

resalta que no se percibe visualmente como elemento estético, atencionalmente.

La simetría visual fue casi nula, con un insignificante aparecimiento al recorrer visualmente las imágenes horizontalmente, de poco valor para la discusión. Las visuales preferidas son aquellas con relieve menos inclinado, con mayor amplitud visual y con varios planos visuales, siempre que el observador esté en un área plana. El observador prefiere ver la riqueza del relieve y de elementos naturales incluyendo laderas de montañas con juegos de luz y sombra. Lo que más prefirieron está entre cuatro y cinco planos de profundidad con tendencia a cuatro. La fotografía que se ve en la Figura 8 carece de valor relacionarla a un punto exacto en el territorio y para la toma de decisiones. También para elaborar conclusiones contundentes respecto a la no preferencia debido a la presencia de propaganda política (Guatemaltecos se unen y piden la renuncia 


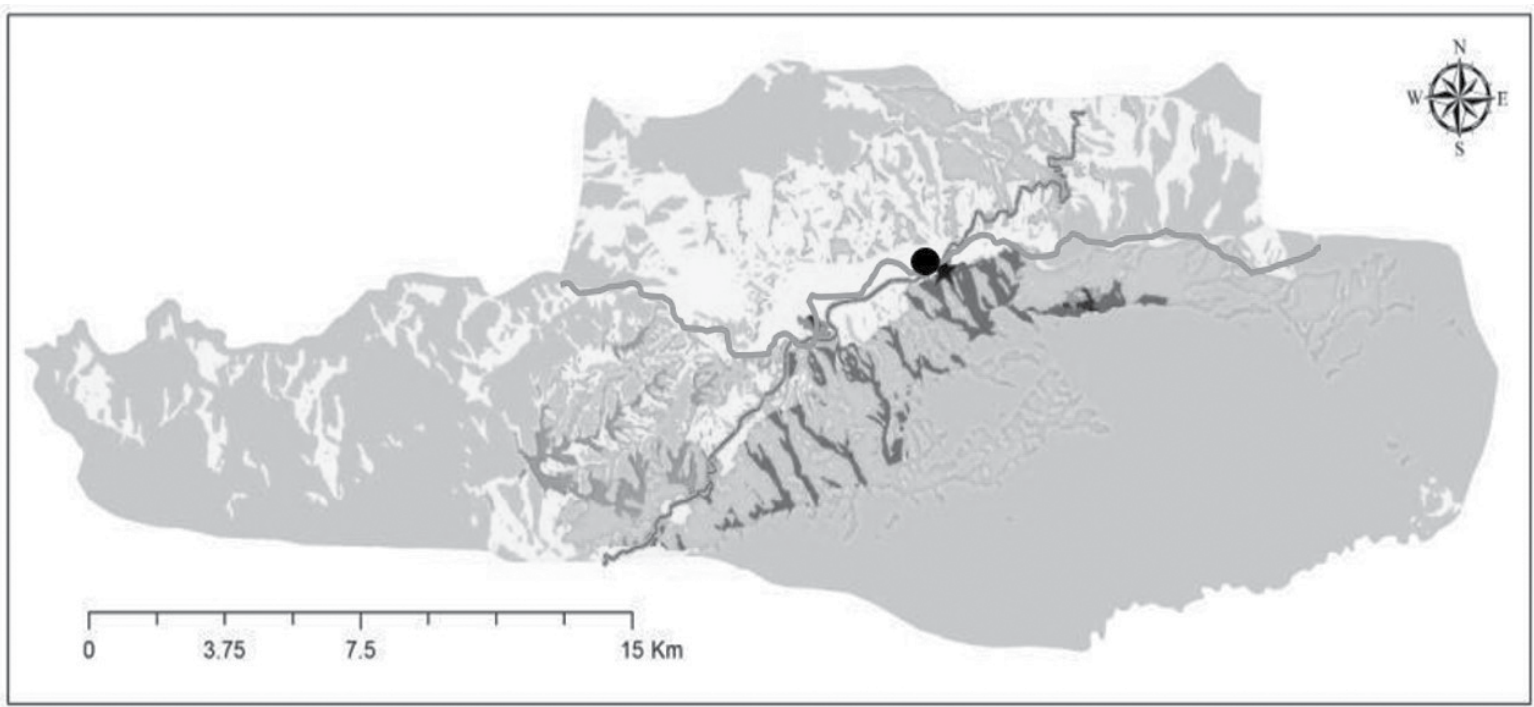

\section{Leyenda}

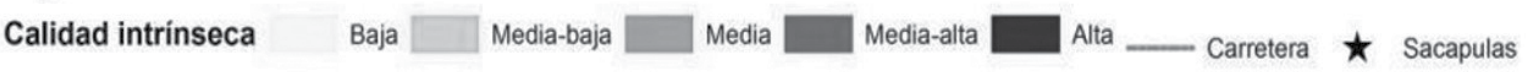

Figura 8. Índice de calidad visual intrínseca por unidad de paisaje.

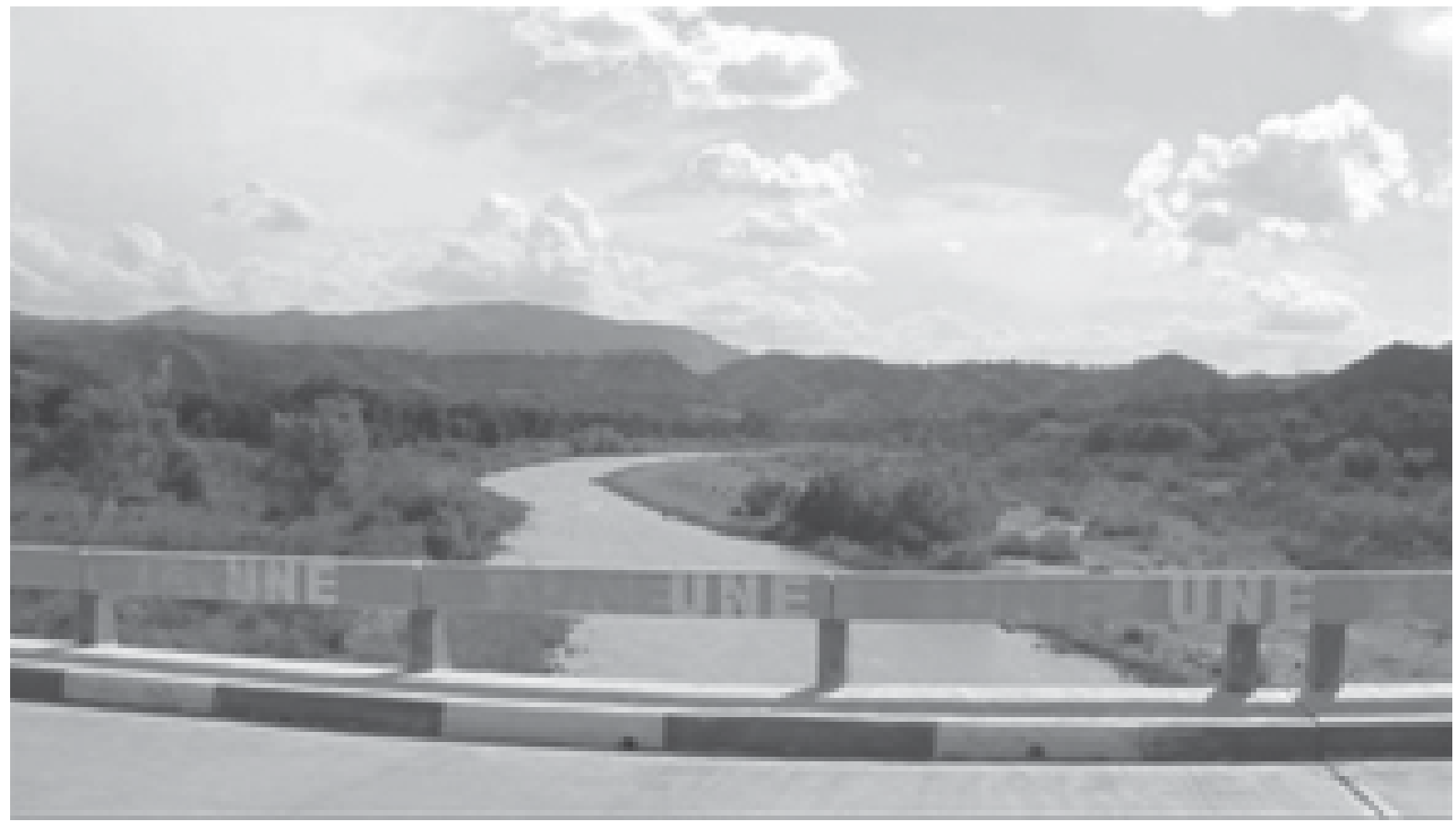

Figura 9. Baranda de puente con aplicación de colores y emblemas de progaganda con fondo depaisaje característico sacapulteco que integra al rio Negro, símbolo del lugar.. 
del presidente, 2015). La presencia de propaganda del partido oficial puede llegar a sesgar la opinión de los informantes.

Para valorar la calidad del paisaje se obtuvieron resultados para las seis unidades por medio de matrices. Estos resultados, al igual que los de la fragilidad visual no representaron ninguna contradicción entre los parámetros usados y factores culturales locales, situación que favoreció la metodología aplicada. Todos estos elementos están relacionados en el campo de la estética ambiental, dentro del proceso o programas en los que este estudio se enmarca (Álvaro, Garrido, \& Torregrosa, 1996). Los resultados obtenidos al aplicar el método debido a que en Sacapulas, la comunidad define a las montañas y a los puntos elevados del territorio como lugares donde habitan los espíritus (J. Vázquez, comunicación personal, junio 2015) y fuerzas sobrenaturales muy respetadas, lo cual implica una valoración hacia el relieve pronunciado, por lo cual no modificaron los parámetros originales planteados por la metodología en puntos básicos como aquellos que indican que un relieve con elevaciones tiene más valor que uno plano. $\mathrm{Al}$ contrario, parece converger, por eso no hay necesidad de aclarar los resultados de las valoraciones en ese sentido: las montañas.

Así mismo para la etnia sacapulteca han sido lugares preservados para la recarga hídrica por lo que han evitado su ocupación, sin embargo, esta visión no ha sido respetada por nuevos habitantes pertenecientes a otras etnias, específicamente la etnia quiché, llegados en décadas recientes. Para fines de este estudio, por ejemplo, los sacapultecos valoran también la cobertura vegetal y la variedad de la misma, así como la presencia de cuerpos de agua y la cantidad en la que se encuentra, esto para mencionar y valorar las condiciones locales en que se da el estudio. Los análisis de visibilidad aquí son un elemento básico a tomar en cuenta en la consideración visual del paisaje y su manejo estratégico, donde un sector evidente es el turístico, sin embargo, lo es también para otros no tan evidentes por plantear los diferentes grados de visibilidad y por ende de capacidad de acogida que tienen la visualización del entorno. Con dicho análisis los tomadores de decisiones y la comunidad en general cuentan con los puntos exactos del territorio o del paisaje, desplegados en material una cartografía espacialmente explícita. Esto permitirá actuar tomando en cuenta las características del entorno exactamente ubicadas consultables en los documentos cartográficos. Esto se hace en otros países ya como una práctica bien establecida y que beneficia los procesos de toma de decisiones e intervenciones en el paisaje.
(Gómez, 2012). La valoración más elevada dada a las unidades 5 y 4 se debe a la cercanía de cuerpos de agua a dichas unidades en donde la presencia del río Negro es cercana y facilita muchas de las actividades necesarias para la vida al mismo tiempo que crea un entorno más verde que se expresa en la presencia de elementos vegetales como el bosque de galería y mosaicos de cultivos, debiendo recordarse que la característica de presencia vegetal forestal fue uno de los aspectos más valorados en el estudio psico semiótico, además de haber sido 2015 una año de sequía (ONU, 2015).

\section{Nivel 3. Elementos primarios de la percepción para la toma de decisión:}

Elementos antrópicos habitacionales: Los cálculos por medio de ordenador han arrojado un nivel de calidad intrínseca (Figura 8) constituido por otros análisis los cuales han sido confirmados por las observaciones de la población.

El elemento vegetal es uno de los más importantes para el sostenimiento de la calidad que ahora arrojan los datos. La calidad calculada para el nivel de intervención humana dentro del paisaje debe verse como un dato que cambiará debido a la necesidad de la población de acceder a soluciones habitacionales y alta tasa de natalidad del lugar, las cuales implican el aumento de cobertura de otra serie de infraestructura. El municipio tuvo un 35.94 contra un 24.5 para la República (Instituto Nacional de Estadística, 2015). Con solo estos dos aspectos comentados ya se puede prever una variación lógica de la calidad visual en el territorio. Si el uso del paisaje se limitara a visualizarlo no se tendría mayor degradación, pero ni siquiera usos amigables o de bajo impacto como el turismo pueden ser considerados tan inocuos y por otro lado la urbanización, una actividad en constante crecimiento, es una de las actividades humanas que más dañan el territorio después de la minería a cielo abierto como lo deja ver Preul (2001).

En la localidad existe un elevado manejo de publicidad por parte de empresas, grupos e instituciones, situación constante que rebasa las coyunturas como el período electoral que se estaba dando durante el desarrollo de la investigación. En tal sentido, es importante para futuras investigaciones, determinar el nivel de valor o antivalor que la gente provee a dicha publicidad. Deberán incluirse otros análisis para valoración de focos de basura, presencia de animales domésticos, salvajes o vectores; estado de la infraestructura urbana 
y domiciliar; presencia de torres o antenas repetidoras de frecuencias, cableado eléctrico, drenajes u otros sistemas expuestos visualmente. Es evidente que los mecanismos atencionales del ser humano hacen intangibles los elementos de cada composición que carecen de interés o utilidad en el momento de la lectura de un paisaje. Estos mecanismos de "ceguera por desatención”, como los llaman Kolb y Whishaw (2006), se activan cuando la atención está focalizada en otra tarea priorizada por su importancia, simbolismo o utilidad. Por ejemplo, la captación de elementos que gustan de una escena sucede mientras se omiten perceptualmente otros "sin importancia", como las infraestructuras urbanas. La Figura 9 ilustra este fenómeno.

Esta escena ocupó el tercer lugar de preferencia, a pesar de tener en primer plano la baranda de concreto de un puente pintado con propaganda. Dicho esto, ya sea por legislación o por la ventaja del funcionamiento de la atención humana o tantos procesos cognitivos más, el paisaje demanda protección real, por lo que los hallazgos deben incorporarse a la planificación territorial local en cuanto sea posible, antes de perder vigencia.

Lo más importante son las conclusiones que puedan repercutir en decisiones políticas en instancias como la reunión del Consejo Internacional de Museos (ICOM), en Milán, Italia, llevada a cabo en julio de 2016, donde se tratan temas como el paisaje cultural, tema vigente en Organización de las Naciones Unidas para la Educación, la Ciencia y la Cultura (Unesco) o en instancias locales como el Ministerio de Cultura y Deportes de Guatemala, en donde pueden hacerse declaraciones de región como paisaje cultural: una declaratoria oficial de protección dentro de la legislación de patrimonio y en alguna unidad técnica en de la municipalidad de Sacapulas, en la Facultad de Agronomía, para que se involucre más con las unidades técnicas de las municipalidades, para que conozcan el potencial de sus municipios (Porras, Comunicación personal, octubre 2015):

Por lo anterior es urgente una Ley de Ordenamiento Territorial resaltando la importancia de este tipo de estudios como insumos para las instituciones $\mathrm{y}$ tomadores de decisiones que tengan incidencia en la valoración, reglamentación y cuidado el paisaje. Dicha ley debería incluir indicadores sobre (a) vegetación y uso del suelo, (b) agua superficial, (c) incidencia antrópica y (d) singularidad. Lo anterior es importante sobre todo en cuanto a potenciales de uso de suelo si se tiene identificado en todas las unidades el potencial de la actividad turística debido a la carretera de baja velocidad con importantes puntos emisores de visuales. Existen actividades que son evidentemente aconsejables por su bajo impacto en el entorno como: hospedaje, servicios de guía, senderismo peatonal y ciclístico, observación de aves y mamíferos endémicos, observación del bosque seco que posee cactáceas, además las unidades 1 , 2 y 3 tienen potencial para manejo forestal siempre y cuando este sea consecuente con las condiciones locales. El turismo comunitario es una de las principales actividades aconsejadas, ya que, tanto por la parte de arquitectura como por la parte de la biología encuentran aquí un importante remanente de elementos con potencial en los diferentes capitales de desarrollo. Se debe tener en cuenta que El Quiché, es uno de los departamentos con más bajo índice de desarrollo humano en Guatemala (Programa de las Naciones Unidas para el Desarrollo, 2012).

Como se mencionó al principio, las consideraciones de lo paisajístico en estos últimos años pasan por la atención al aspecto de la gestión, sin el cual resultados de investigaciones o legislación no podrían articularse con la práctica. En este importante aspecto entonces se puede decir que los resultados de este estudio cumplen con el aspecto planteado en la carta Iberoamericana del Paisaje (Unesco, 2012) en los aspectos como documentar el paisaje y sus vulnerabilidades a través de una rigurosa recopilación accesible. En cuanto a esto, se debe decir que aquí se logró proporcionarla de manera atractiva por medio de la cartografía de un GIS, generando herramientas de diagnóstico, desarrollo y evaluación que integra la visión técnica con el sentir de las comunidades. También se debe decir que se han aplicado instrumentos de análisis bajo los criterios de visibilidad y sostenibilidad para que los tomadores de decisiones puedan incidir en el nivel de desarrollo de la población, integrando estos resultados en la práctica del ordenamiento territorial consecuente con valores geo morfológicos, medio ambientales, bióticos, sociales y culturales que sufren agresiones constantemente a veces simplemente por la inexistencia de los más básicos planes de intervención. Como menciona dicha carta, es necesario contar con las miradas especializadas para la conservación y la erradicación de la pobreza.

En este estudio participaron actores locales que buscan la integración de acciones públicas que incluyan su visión, cooperantes, diversas instituciones, actores sociales insertos en la gestión de paisajes, como municipalidad y universidad para compartir responsabilidades y apoyos. La visión de los actores locales es importante pues integra la relación histórica y actual 
del grupo social la cual muchas veces no está incluida en metodologías foráneas o técnicas. En la metodología, se tomó en cuenta la sostenibilidad para plantear la vulnerabilidad como determinante del paisaje. Se valoraron los patrimonios paisajísticos culturales y naturales para la toma de decisiones, dando importancia a la gestión independiente de los ciclos eleccionarios, y así garantizar su permanencia y estabilidad. Se entendió la globalización como un agente reductor de elementos de identidad, y ya que esta se expande, es importante la protección del paisaje cultural. Para la sostenibilidad, se resaltó la importancia de la planificación, así como la generación de indicadores para monitoreo de cambios. Por tal motivo, es vital el compromiso de los actores sociales. Como los tomadores de decisiones locales tanto públicos como privados, es decir profesionales de la planificación en municipalidades y ministerios, desarrolladores de turismo o de las cámaras que aglutinan empresas etc.

Por último, los resultados de este trabajo atienden a lo planteado en el II Encuentro Iberoamericano del Paisaje (Unesco, 2012), que reconoce al paisaje como importante para el desarrollo integral y sostenible de la población, mejora de su calidad de vida y reforzamiento de su identidad con los antecedentes de las cartas Latinoamericanas del paisaje, Carta Argentina del Paisaje, Carta Costarricense del Paisaje, Carta Mexicana del Paisaje, Carta Brasileña del Paisaje.

\section{Agradecimientos}

Esta investigación fue cofinanciada por Digi-Uasc-2015, Proyecto: 4.8.63.227.

\section{Referencias}

Arc Map (versión 10) [Software de computación]. California : ESRI.

Aguilera, I., Batista, Y. Bastola, S., \& Rojas, L. (2016). Impacto visual generado por la explotación minera en el yacimiento Punta Gorda, Moa. Minería y Geología, 32, 144.

Álvaro, J. L., Garrido, L., \& Torregrosa, J. R. (1996). Psicología social aplicada. Madrid: McGraw Hill.

Alternativa. (2010). Campaña 10,000 compromisos por el agua. Recuperado de https://10000compromisosporelagua.wordpress.com/
Briceño, M., Contreras, W., \& Owen, M. (2012). Atributos eco-estéticos del paisaje urbano. Luna Azul, 34, 26-49.

Bollo Manent, M., Hernández Santana, J. R., \& Méndez Linares, A. P. (2010). Evaluación de potencialidades naturales en el ordenamiento ecológico territorial: Noroeste del Estado de Chiapas, México. Boletín de la Asociación de Geográfos Españoles, 53, 191-218

Cano, N. (2006). Paisaje y desarrollo sostenible. El ejemplo de la implantación de la agenda 21 en las zonas rurales de Bizcaia. Kobie Antropología Cultura, 12, 71-86.

Environmental Systems Research Institute. (2012). ArcGIS: Release 10.1. Redlands, California: Autor.

Ferraro, R., \& Zulaica, L. (2011). Potencialidades y limitaciones ambientales en el área de interfase urbana-rural de la ciudad de Mar del Plata (provincia de Buenos Aires, Argentina): Una contribución al ordenamiento territorial. Revista Geográfica de América Central, (Número Especial EGAL), 1-19.

Guatemaltecos se unen y piden la renuncia del Presidente. Prensa Libre. Recuperado de http:// www.prensalibre.com/guatemala/politica/ mas-de-100-mil-guatemaltecos-piden-la-renuncia-de-perez-molina

Google. (s.f.). [dirección de Google Maps para ??,??]. Recuperado de August 4, 2015, de https://goo. $\mathrm{gl} / \mathrm{maps} / \mathrm{ILt} 8 \mathrm{O}$

Gómez, A. (2012). El paisaje: Diseño de una metodología para su análisis, planificación e inclusión en los procesos de toma de decisiones (Tesis de doctorado). Universidad Politécnica de Madrid. Recuperado de http://oa.upm.es/13532/2/ALEJANDRO_GOMEZ_VILLARINO_2.pdf

Instituto Nacional de Estadística. (2015). República de Guatemala: Estadísticas demográficas y vitales 2014. Guatemala: Autor

Jung, C. G. (1959). Volume 9.1: The Archetypes of the collective unconscious. En C. G. Jung, Obra completa. 1934-1954. Recuperado de https://archive.org/stream/collectedworksof91cgju\#page/ n3/mode/2up

Kolb, B., \& Whishaw, I. (2006). Neuropsicología humana. Madrid: Médica Panamericana. 
La O, J. A., Salinas, E., \& Licea, J. E. (2012). Aplicación del diagnóstico geoecológico del paisaje en la gestión del turismo litoral. Caso Destino Turístico Litoral Norte de Holguín, Cuba. Investigaciones Turísticas, 3, 1-18.

Marín-Yaseli, M., \& Nogués-Bravo, D. (2001). La potencialidad turística del medio natural en El Lic de las sierras ibéricas riojanas mediante evaluación multicriterio. Zubia Monográfico, 13, 227-240.

Másmela, P. (2010). El paisaje como elemento de ordenación territorial. Un análisis de paisaje desde su enfoque visual en el borde centro oriental de $\mathrm{Me}$ dellín, Colombia (Tesis de maestría). Universidad Nacional de Colombia, Facultad de Arquitectura, Medellín.

Paz, M., Escribano, R., López, R., \& Sánchez, P. (2005). Cartografía del paisaje de la comunidad autónoma de La Rioja. España: Universidad Politécnica de Madrid. Recuperado de http://www.larioja. org/territorio/es/ordenacion-territorio-urbanismo/ paisaje/estudio-cartografia-paisaje enciclopedia pag29

Preul, H. C. (2001). Control de contaminación del agua. En J. Spiegel, \& L. Y. Maystre (Eds.), Control de la contaminación ambiental (55.2655.38). Madrid: Ministerio Trabajo.

Priego, A., Bocco, G., Mendoza, M., \& Garrido, A. (2008). Propuesta para la generación semiautomatizada de unidades de paisajes: Fundamentos y métodos (Serie Planeación Territorial). México: Secretaría de Medio Ambiente y Recursos Naturales, Instituto Nacional de Ecología, Centro de Investigaciones en Geografía Ambiental, Universidad Nacional Autónoma de México.
Programa de las Naciones Unidas para el Desarrollo. (2012). Informe Desarrollo Humano sobre Guatemala. Guatemala: Autor.

Sánchez, D. (2007). Nuevos retos de la planificación territorial y desarrollo sostenible en México: Una perspectiva comparada. Convergencia, (47), 320.

Secretaría General de Planificación Nacional \& Consejo Municipal de Desarrollo de Cuicuilco.(2010). Plan desarrollo municipal Cuicuilco, Huehuetenango. Guatemala: Autor

Silva Pérez, R. (2014). Caracterización de paisajes en pequeñas y medianas ciudades. Propuesta metodológica aplicada a Constantina (Sierra Norte de Sevilla). Boletín de la Asociación de Geográfos Españoles, 64, 297-319.

Véliz, M., \& Méndez, C. (2008). Análisis comparativo de la diversidad florística y endemismos de la zona semiárida de Guatemala (FODECYT No. 2006-27). Guatemala: Consejo Nacional de Ciencia y Tecnología, Universidad de San Carlos de Guatemala, Facultad Ciencias Químicas y Farmacia. 